\title{
Inferior Pancreatico-Duodenal Artery Aneurysm with Superior Mesenteric Artery Stenosis
}

\author{
Alin-Cornel Fetti ${ }^{1,2}$, Vlad Radu Puia ${ }^{1,2}$, Mihai Comșa ${ }^{1}$, Marius Horațiu Stanca ${ }^{1,2}$, Aida Puia ${ }^{2}$, Nadim Al Hajjar ${ }^{1,2}$
}

1) Regional Institute of

Gastroenterology and

Hepatology, Cluj-Napoca

2) Iuliu Haţieganu University

of Medicine and Pharmacy,

Cluj-Napoca, Romania

\author{
Address for correspondence: \\ Aida Puia \\ Iuliu Hatieganu University of \\ Medicine and Pharmacy \\ 8 Victor Babes Street, \\ Cluj-Napoca, 400012, \\ Romania \\ Draidapuia@gmail.com
}

\begin{abstract}
Pancreatico-duodenal artery aneurysm (PDAA) associated with stenosis or occlusion of the celiac trunk is a rare condition. Furthermore, PDAAs associated with stenosis of the superior mesenteric artery (SMA) are even more uncommon, with only six cases reported in the literature. We report a case of a 61-year old male patient who presented with hematemesis, haematochezia and haemorrhagic shock. The upper gastrointestinal endoscopy revealed an ulcerous lesion at the third portion of the duodenum, without achieving the haemostasis. The emergency laparotomy (suture of the lesion and gastro-entero-anastomosis) permitted temporary haemostasis. Computed tomography angiography identified the PDAA ruptured into the third portion of the duodenum and the SMA stenosis at its origin; a dense network of collateral vessels was present. The patient was successfully managed with coil embolization. Short and mid-term follow-up were without incidents.
\end{abstract}

Key words: upper gastrointestinal bleeding - pancreaticoduodenal artery aneurysm - stenosis of the superior mesenteric artery - coil embolization.

Abbreviations: CT: computed tomography; DSA: digital subtraction angiography; IPDAA: inferior pancreatico-duodenal artery aneurysm; PDAA: pancreatico-duodenal artery aneurysm; SMA: superior mesenteric artery; VAA: visceral artery aneurysm.

\section{INTRODUCTION}

Pancreatico-duodenal artery aneurysms (PDAAs) are rare, accounting for less than $2 \%$ of all visceral aneurysms [1]. In addition, inferior PDAA (IPDAA) are exceedingly rare. This specific type of aneurysm represents a challenge both for diagnosis and management, especially in emergency, due to their high mortality rate [2, $3]$. The incidence of ruptured aneurysms is $65 \%$ with an operative mortality rate between $36-50 \%$ [3-5].

Depending on etiopathogenetic factors PDAAs can be divided in true or false aneurysms. False PDAAs occur after trauma or inflammatory processes such as pancreatitis. True PDAAs are the results of vessel wall abnormalities or are related to atherosclerosis [6]. Sutton et al. [7] reported that true PDAAs are related with celiac stenosis or occlusion, $80 \%$ of the cases having celiac stenosis [7]. Celiac artery stenosis or occlusion may determine increased blood flow in the pancreatic arcades and can contribute to the development of true PDAAs. Stenosis of the superior mesenteric artery (SMA) may also induce hemodynamic stress in the pancreatico-duodenal arcades and lead to a true PDAA development. Pancreatico-duodenal artery aneurysms associated with SMA stenosis are extremely rare, with only six cases reported in the literature [8-13].

The new imaging techniques facilitates the diagnosis of PDAA. To date there is no established definitive treatment strategy. Different treatment methods are recommended, including endovascular interventions and surgical procedures. We present a case with IPDAA and rupture into the duodenum, associated with SMA stenosis, successfully treated with coil embolization.

\section{CASE REPORT}

A 61-year old male patient presented in the emergency department with hematemesis, haematochezia and haemorrhagic shock. His comorbidities included morbid 
obesity, essential hypertension, alcoholic cardiomyopathy, atrial fibrillation, diabetes mellitus. He reported several episodes of melena without bleeding source identification. He had no episode of acute pancreatitis.

Emergency upper gastrointestinal endoscopy revealed an ulcerous lesion of $1.5 \mathrm{~cm}$, with active bleeding, located in the third portion of the duodenum; the haemostasis could not be achieved through endoscopy. An emergency laparotomy was performed; a longitudinal duodenotomy revealed the ulcerous lesion with active bleeding. Efficient haemostasis was obtained by suturing the lesion, duodenorrhaphy and gastro-entero-anastomosis. The evolution was favourable until the $8^{\text {th }}$ day, when he presented melena without hemodynamic impact. Emergency upper gastrointestinal endoscopy did not reveal any active bleeding sources. The Computed tomography (CT) angiography revealed a $10 \mathrm{~mm}$ aneurysm of the inferior pancreatico-duodenal artery that was fed from a network of collateral vessels emerging from branches of the gastroduodenal and superior mesenteric artery (Fig. 1). A $50 \%$ focal stenosis of the SMA was also depicted. A microcoil angio-embolization of the aneurysm was scheduled. The microcatheter was supra-selectively inserted in the collateral arcade that originated from the first jejunal branch of the SMA and was linked with the celiac trunk through a branch of the gastroduodenal artery. At this level the aneurysm presented some straight arterial branches that supplied the duodenal wall (Fig. 2). The aneurysm was surpassed $15 \mathrm{~mm}$ with the

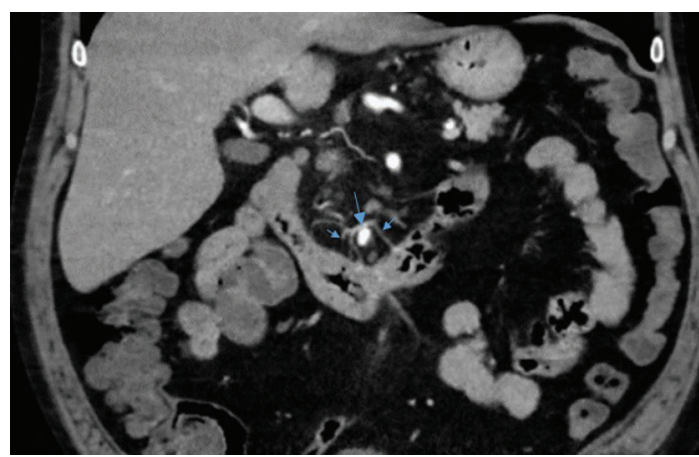

Fig. 1. CT angiography: a $10 \mathrm{~mm}$ aneurysm (large arrow) and straight branches (small arrows) that open-up in the third portion of the duodenum.

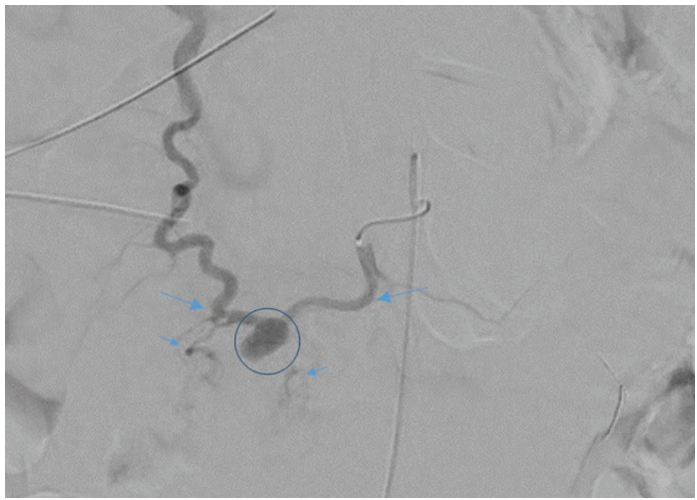

Fig. 2. CT angiography: collateral arcade that originates from the first jejunal artery (large arrow) of the superior mesenteric artery and is linked with the celiac trunk through a branch (large arrow) of the gastroduodenal artery; sacciform aneurysm (encircled); straight arterial branches which supply the duodenal wall (small arrows) catheter and the first hemostatic micro-coil was applied at this level. The 5 min digital subtraction angiography (DSA) control confirmed downstream flow interruption. Fifteen $\mathrm{ml}$ of Gelaspon (Scrofalon standard 8x5x1) was injected. The second micro-coil was applied at $30 \mathrm{~mm}$ upstream of the aneurysm and the second DSA control after 5 min confirmed there was no flow in the embolized territory, with the complete disappearance of the pathological vessels that supplied the duodenal wall (Fig.3).

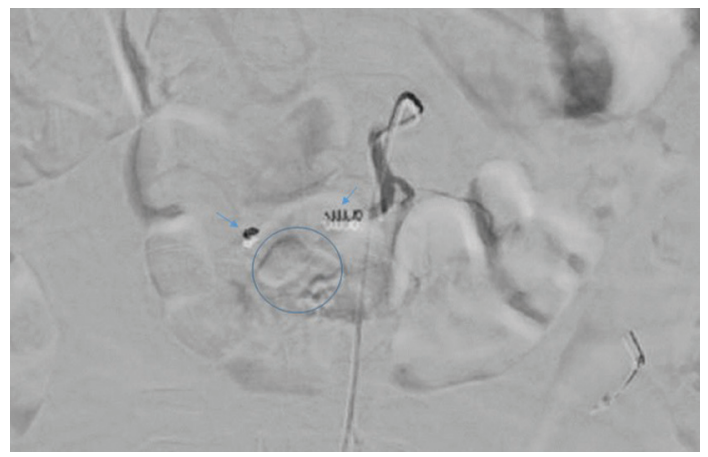

Fig. 3. Micro-coil angio-embolization: hemostatic micro-coils applied (arrow) with upstream and downstream flow interruption and flow disruption in the embolized territory, with the complete disappearance of the pathological vessels supplying the duodenal wall (encircled area).

\section{DISCUSSION}

The incidence of true aneurysms (2\%) is equal in males and females, and in terms of age they are found in a broad range with an average of 60 years [14]. True pancreatico-duodenal artery aneurysms are very rare; the etiological factors include atherosclerosis, collagen diseases and most important, stenosis or occlusion of a major artery trunk, mainly the celiac trunk [15]. True aneurysms are often difficult to distinguish from false aneurysms.

Several aspects suggest that our patient had a true aneurysm of the pancreatico-duodenal artery: there was no past history of pancreatitis or trauma, relation with the SMA stenosis and the extensive arterial network connecting the superior mesenteric artery to the celiac artery. The pathogenesis of the aneurysm is considered to be an increased blood flow from the celiac artery to the SMA via the superior anterior and posterior pancreaticoduodenal arteries, as described by other authors [9]. The cause of SMA stenosis was the arteriosclerosis in our case. From the other six cases published in the literature only one described the cause of the obstruction as SMA thrombosis [13]; in the other cases the cause was not clarified [8-12].

Once the PDAA has been diagnosed, prompt treatment was reported to be decisive because the rupture is independent of the size of the peripancreatic artery aneurysm [16]. Our patient had a rather small aneurysm, $10 \mathrm{~mm}$ in diameter. Most PDAAs, apart from the aortic ones, range from 8 to $30 \mathrm{~mm}$ in diameter [17]. The PDAAs generally rupture into the retroperitoneal space, but also in the peritoneal cavity or, exceptionally, into the digestive tract, the duodenum $[18,19]$. In our case, the aneurysm ruptured in the third portion of the duodenum. In 
the other six cases with PDAA and SMA stenosis described in the literature, only one case had a rupture of the aneurysm, in the retroperitoneum [13].

There is a debate in the literature regarding the current management of PDAAs; it depends on the clinical presentation, comorbidities and risk factors [20]. The methods used include surgery (vessel ligation, aneurysm suture, pancreatic parenchyma resections, revascularization or by-pass procedures), embolization therapy, as well as the necessity of the treatment of associated artery trunk lesion, which remains unclear. Surgical treatment is indicated for ruptured or large aneurysms, aneurysms supplied by several vessels, for which embolization is not feasible or inaccessible [21,22] These lesions have a high risk of rupture regardless of their size. Intraoperative isolation and control can be complicated and hazardous. Embolization has become the method of choice for symptomatic or ruptured visceral artery aneurysms VAAs $[14,23]$, and the first line of treatment in emergency with a very low rate of morbidity and mortality [24]. Endovascular treatment is a safer alternative to open surgical management, particularly in ruptured aneurysms, being associated with a lower mortality rate $(2.7 \%$ vs $23.7 \%)$ [25]. Even though percutaneous techniques have become the first choice in the management of aneurysms, they are not without risks such as aneurysm rupture during catheterization and ischemia of visceral organs [26]. However, success rates for embolization have been reported to be as high as $67 \%-100 \%[27,28]$.

In our case, selective catheterization and micro-coil packing of the aneurysm was accomplished and the feeding vessels were selectively embolized using micro-coils from the SMA. Transcatheter arterial embolization has been used for treatment of PDAA accompanied by SMA stenosis in two cases $[10,13]$ out of six published in the literature, probably because of the concern of bowel ischemia following embolization and difficult catheterization. In only one case, simultaneous treatment of the SMA stenosis with a percutaneous transluminal angioplasty using a balloon catheter was done [10]. Regarding our patient we considered unnecessary any treatment of the associated SMA stenosis as the stenosis did not exceed $50 \%$ of the lumen; the existing data from the literature suggested no recurrence of the PDA aneurysms secondary to residual celiac trunk stenosis [29].

\section{CONCLUSION}

This report illustrates a rare case of PDAA associated with stenosis of the SMA, complicated with a duodenal rupture and manifested as gastrointestinal bleeding. These specific types of aneurysms remain a poorly defined entity, with challenging diagnosis and treatment. Catheter embolization might be an effective therapeutic technique, safer than open surgical repair.

Conflicts of interest: None to declare.

Authors' contribution: A.C.F, V.R.P. conceived and wrote the manuscript. M.C., A.C.F, V.R.P. managed the patient. M.H.S. analysed and reviewed the data. A.P. drafted the work. N.A.H. critically revised the paper. All authors approved the final version of the manuscript.

\section{REFERENCES}

1. Williamson J, Cook J, Jackson J, Hocken DB. Infective aneurysm of the inferior pancreaticoduodenal artery. Ann R Coll Surg Engl 2011;93:e87e88. doi:10.1308/147870811X590991

2. Hossain A, Reis ED, Dave SP, Kerstein MD, Hollier LH. Visceral artery aneurysms: experience in a tertiary-care center. Am Surg 2001;67:432 437.

3. Neschis DG, Safford SD, Golden MA. Management of pancreaticoduodenal artery aneurysms presenting as catastrophic intra-abdominal bleeding. Surgery 1998;123:8-12. doi:10.1016/S00396060(98)70222-3

4. Formentini A, Birk D, Kunz R, Orend KH, Beger HG. Inferior pancreaticoduodenal artery aneurysm as a consequence of traumatic acute pancreatitis. A case report and review of the literature. Int J Pancreatol 1997;21:263-267.

5. Ricci G, Riu P, Attina GM, et al. Endovascular treatment of ruptured pancreaticoduodenal artery aneurysm: The importance of collateral vessels. A case report. Int J Surg Case Rep 2017;41:205-208. doi:10.1016/j.ijscr.2017.10.036

6. Rockman CB, Maldonado TS. Splanchnic Artery Aneurysms. Philadelphia: Saunders, 2005.

7. Sutton D, Lawton G. Coeliac stenosis or occlusion with aneurysm of the collateral supply. Clin Radiol 1973;24:49-53. doi:10.1016/s00099260(73)80114-x

8. Ichinokawa M, Iwai K, Matsumura Y, et al. A case of the anterior superior pancreaticoduodenal artery aneurysm with complete occlusion of the superior mesenteric artery. Jpn J Gastroenterol Surg 2006;39:1678-1682.

9. Kimura C, Adachi H, Yamaguchi A, et al. A case of an unruptured inferior pancreaticoduodenal artery aneurysm with celiac aretery occlusion and superior mesenteric aretery stenosis. Jpn J Vasc Surg 2009;18:691-694.

10. Ikoma A, Nakai M, Sato $M$, et al. Inferior pancreaticoduodenal artery aneurysm treated with coil packing and stent placement. World J Radiol 2012;4:387-390. doi:10.4329/wjr.v4.i8.387

11. Takao H, Doi I, Watanabe T, Yoshioka N, Ohtomo K. Natural history of true pancreaticoduodenal artery aneurysms. Br J Radiol 2010;83:744746. doi:10.1259/bjr/17700576

12. Kitaoka T, Deguchi J, Kamiya C, Suzuki J, Sato O. Pancreaticoduodenal artery aneurysm formation with superior mesenteric artery stenosis. Ann Vasc Dis 2014;7:312-315. doi:10.3400/avd.cr.14-00040

13. Saaraswat B, Saaraswat V, Mishra S, Adler M, Chandra P, Barzani Y. Inferior Pancreaticoduodenal Artery Aneurysm with Superior Mesenteric Artery Occlusion - An Extremely Rare Case of Visceral Artery Aneurysms. The Internet Journal of Surgery 2010;26(2):1-6.

14. Coll DP, Ierardi R, Kerstein MD, Yost S, Wilson A, Matsumoto T. Aneurysms of the Pancreaticoduodenal Arteries: A Change in Management. Ann Vasc Surg 1998;12:286-291. doi:10.1007/ s100169900155

15. Quandalle P, Chambon JP, Marache P, Saudemont A, Maes B. Pancreaticoduodenal artery aneurysms associated with celiac axis stenosis: report of two cases and review of the literature. Ann Vasc Surg 1990;4:540-545. doi:10.1016/S0890-5096(06)60835-2

16. Moore E, Matthews MR, Minion DJ, et al. Surgical management of peripancreatic arterial aneurysms. J Vasc Surg 2004;40:247-253. doi:10.1016/j.jvs.2004.03.045

17. De Perrot M, Berney T, Deleaval J, Buhler L, Mentha G, Morel P. Management of true aneurysms of the pancreaticoduodenal arteries. 
Ann Surg 1999;229:416-420. doi:10.1097/00000658-19990300000016

18. Kadir S, Athanasoulis CA, Yune HY, Wilkov H. Aneurysms of the pancreaticoduodenal arteries in association with celiac axis occlusion. Cardiovasc Radiol 1978;1:173-177. doi:10.1007/bf02552029

19. Vernhet J, Corcos J. Aneurysms of the pancreaticoduodenal arteries. Chirurgie 1982;108:617-624.

20. Udd M, Leppaniemi AK, Bidel S, Keto P, Roth WD, Haapiainen RK. Treatment of bleeding pseudoaneurysms in patients with chronic pancreatitis. World J Surg 2007;31:504-510. doi:10.1007/s00268-006-0209-Z

21. Marone E, Mascia D, Kahlberg A, Brioschi C, Tshomba Y, Chiesa $\mathrm{R}$. Is open repair still the gold standard in visceral artery aneurysm management? Ann Vasc Surg 2011;25:936-946. doi:10.1016/j. avsg.2011.03.006

22. Holzapfel K, Eiber M, Rummeny E, et al. Pancreaticoduodenal artery aneurysms: a rare but dangerous entity. Cardiovasc Intervent Radiol 2013;36(S284):0174-1551

23. Carr SC, Pearce WH, Vogelzang RL, McCarthy WJ, Nemcek AA Jr Yao JS. Current management of visceral artery aneurysms. Surgery 1996;120:627-634. doi:10.1016/s0039-6060(96)80009-2
24. Salam TA, Lumsden AB, Martin LG, Smith RB 3rd. Nonoperative management of visceral aneurysms and pseudoaneurysms. Am J Surg 1992;164:215-219. doi:10.1016/s0002-9610(05)81073-6

25. Thony F, Rodiere M. Epidemiology and indications for treatment of visceral arteryaneurysms. Cardiovasc Intervent Radiol 2013;36:01741551.

26. Guijt M, van Delden OM, Koedam NA, van Keulen E, Reekers JA. Rupture of true aneurysms of the pancreaticoduodenal arcade: treatment with transcatheter arterial embolization. Cardiovasc Intervent Radiol 2004;27:166-168. doi:10.1007/s00270-003-0113-y

27. Tsai CC, Chiu KC, Mo LR, et al. Transcatheter arterial coil embolization of iatrogenic pseudoaneurysms after hepatobiliary and pancreatic interventions. Hepatogastroenterology 2007;54:41-46.

28. Mandel SR, Jaques PF, Sanofsky S, Mauro MA. Nonoperative management of peripancreatic arterial aneurysms. A 10-year experience. Ann Surg 1987;205:126-128. doi:10.1097/00000658198702000-00004

29. Brocker JA, Maher JL, Smith RW. True pancreaticoduodenal aneurysms with celiac stenosis or occlusion. Am J Surg 2012;204:762-768. doi:10.1016/j.amjsurg.2012.03.001 